\title{
Diagnosis Value of Combined Detection of Serum SF, CEA and CRP in Non-Small Cell Lung Cancer
}

This article was published in the following Dove Press journal:

Cancer Management and Research

Jing Zhou

Xin Diao

Shengyu Wang

Yang Yao (D)

Department of Respiratory and Critical Care, The First Affiliated Hospital of

Xi'an Medical University, Xi'an, Shaanxi

7I0077, People's Republic of China
Correspondence: Yang Yao

Department of Respiratory and Critical

Care, The First Affiliated Hospital of Xi'an

Medical University, X'an, Shaanxi 710077,

People's Republic of China

Tel +86 I5902939063

Email yaoyang1220@sina.com
Introduction: The aim of this study was to evaluate the clinical diagnostic value of combined detection of serum ferritin (SF), carcino-embryonic antigen (CEA) and C-reactive protein (CRP) in non-small cell lung cancer (NSCLC).

Methods: The study included 70 patients with NSCLC, 50 patients with benign lung disease and 50 healthy subjects. The serum concentrations of SF, CEA and CRP were determined by ELISA.

Results: The results showed that the serum levels of SF, CEA and CRP in the NSCLC group were significantly higher than those of the benign lung disease group and the control group. The expression of the above three indexes in the lung cancer group III+IV was higher than that in the I+II group $(P<0.05)$, and the expression of SF, CEA and CRP in the adenocarcinoma group was higher than that in the squamous cell carcinoma group. The difference is statistically significant $(P<0.01)$. When the serum CEA, SF and CRP levels were used alone for diagnosis of NSCLC, CRP had the best diagnostic value. The area under the curve was 0.795 . The diagnostic sensitivity and specificity were $81.8 \%$ and $66.8 \%$, respectivelyWhen combining these three factors, the area under the curve was 0.890 , and the sensitivity and specificity were $80.3 \%$ and $82.5 \%$, respectively. The parameters above were also significantly different (all $P<0.01$ )

Conclusion: This study indicated that the combined detection of serum SF, CEA and CRP could improve the early diagnostic sensitivity of NSCLC, and may be used as a potential diagnostic method for NSCLC.

Keywords: non-small cell lung cancer, serum ferritin, carcino-embryonic antigen, C-reactive protein, combined detection

\section{Introduction}

Lung cancer is one of the most common malignant tumors endangering human health. ${ }^{1,2}$ Non-small cell lung cancer (NSCLC) is the most common type of lung cancer. ${ }^{3}$ In recent years, although surgical treatment and radiochemotherapy have made great progress in the treatment of lung cancer, the 5-year survival rate is only about $10 \%{ }^{4}$ Therefore, early diagnosis is very important for the treatment and prognosis of lung cancer. In recent years, people have been looking for early diagnosis, treatment and prevention methods. Among them, the research and development of tumor markers are particularly rapid, providing a basis for the early diagnosis of lung cancer. However, the examination of a single index has certain limitations. Many scholars emphasize the combined detection of multiple tumor markers to facilitate the early and accurate diagnosis of tumors. 
Serum ferritin (SF) is a kind of macromolecular glycoprotein, which can be caused by inflammation and oxidative stress. In recent years, it has been expressed in lung cancer and other malignant tumors. ${ }^{5,6}$ Carcinogenic antigen (CEA) is an acidic glycoprotein with a specific determinant of human embryonic antigen, which is one of the early tumor markers for NSCLC detection. ${ }^{7,8}$ C-reactive protein (CRP) is a classic non-specific acute phase protein. Many studies have shown that the increase of CRP is positively correlated with the increase of tumor stage. ${ }^{9,10}$ The value of the above three factors in the early diagnosis of lung cancer has been studied, ${ }^{11,12}$ but the combination of these three factors as a method of early diagnosis of lung cancer has not been reported. The purpose of this study is to evaluate the diagnostic value of SF, CEA and CRP in lung cancer, improve the early diagnosis rate of lung cancer and provide a more diagnostic basis for clinicians.

\section{Materials and Methods}

\section{Patients}

The study included 70 NSCLC patients ( 37 males and 33 females, aged 42-79 years) hospitalized in the First Affiliated Hospital of Xi'an Medical University from January 2009 to December 2013. There were 55 smokers and 15 non-smokers. There were 31 cases of squamous cell carcinoma and 39 cases of adenocarcinoma. All patients with lung cancer were diagnosed by chest $\mathrm{CT}$ examination for the first time, lung tissue was taken by surgical operation or lung biopsy under bronchoscope and confirmed by pathological examination, and were not treated by radiotherapy and chemotherapy. In TNM staging according to the 2009 International Association for Lung Cancer Research (IASLC) staging criteria, 13 patients with stage Ia-Ib, 21 patients with stage Ia-IIb, 32 patients with stage IIIa-IIIb and 4 patients with stage IV. The benign lung disease group included 50 patients who were hospitalized ( 28 males and 22 females) during the same period (Table 1). There were 32 cases of COPD, 14 cases of pneumonia and 4 cases of tuberculosis. The control group comprised 50 healthy volunteers ( 24 males and 26 females). There was no significant difference in age, gender and other general data among the three groups $(P>0.05)$.

\section{Biochemical Analyses}

A $5 \mathrm{~mL}$ of fasting venous blood sample was collected from all subjects in the morning before surgery and centrifuged at $2500 \mathrm{r} / \mathrm{min}$ for $10 \mathrm{~min}$, and the separated
Table I Characteristics of Patients with Lung Cancer

\begin{tabular}{|c|c|c|}
\hline Catalog & Lung Cancer Group & $\mathbf{P}$ \\
\hline Age & $57(42-79)$ & \\
\hline Gender & & 0.062 \\
\hline Female & 33 & \\
\hline Male & 37 & \\
\hline Smoker state & & 0.083 \\
\hline Former & 10 & \\
\hline Never & 28 & \\
\hline Current & 32 & \\
\hline Cancer type & & 0.12 \\
\hline Squamous cell carcinoma & 31 & \\
\hline Adenocarcinoma & 39 & \\
\hline TNM & & 0.093 \\
\hline $\mathrm{la}-\mathrm{lb}$ & 13 & \\
\hline la-llb & 21 & \\
\hline Illa-Illb & 32 & \\
\hline IV & 4 & \\
\hline
\end{tabular}

serum was stored in the $-80{ }^{\circ} \mathrm{C}$ refrigerator for testing. The concentrations of SF, CEA and CRP were detected by enzyme-linked immunosorbent assay (ELISA), and the process was strictly in accordance with the instructions of the kit ( $\mathrm{Fu}$ jian blueprint biological reagent $\mathrm{co}$ ). The detection range of the kit was SF: $25 \mathrm{ng} / \mathrm{mL}-800$ ng/mL. CEA: $2.5 \mathrm{ng} / \mathrm{mL}-80 \mathrm{ng} / \mathrm{mL}$; CRP: $1.56 \mu \mathrm{g} / \mathrm{mL}-$ $50 \mu \mathrm{g} / \mathrm{mL}$. Normal reference value: SF: male $80-130$ $\mathrm{ng} / \mathrm{mL}$, female $35-55 \mathrm{ng} / \mathrm{mL}$; CEA $<5 \mathrm{ng} / \mathrm{mL}$; CRP $<10 \mathrm{mg} / \mathrm{mL}$.

\section{Statistical Analysis}

The data were analyzed using SPSS software 18.0 (SPSS Inc., Chicago, IL, USA). Chi-square test or Fisher's exact test was used for analysis of categorical variables. The ANOVA test or Student's $t$-test was utilized to compare measurement variables. The F-test was used if related to non-normal distribution parameters. Categorical variables were expressed as number (\%) and mean (SD). Multivariate logistic regression analysis was used. The diagnostic values of SF, CEA and CRP in the lung cancer and benign disease groups were evaluated by ROC curve (receiver operating characteristic, ROC) and calculated area under the curve (AUC). The cut-off point corresponding to the maximum Youden index was taken as the best clinical critical point for diagnosis. $P<0.05$ was considered statistically significant. 


\section{Result}

Comparison of Serum CEA, SF and CRP

\section{Levels in Each Group}

As shown in Table 2, compared with the control group, the serum concentrations of SF, CEA and CRP in patients with lung cancer and benign lung disease were significantly increased and the difference was statistically significant $(P<0.01)$; the expression levels of SF and CEA in the lung cancer group were significantly higher than those in the benign lung disease group $(P<0.01)$.

\section{Comparison of the Relationship Between Serum CEA, SF and CRP Levels with Smoking Status and Gender}

As shown in Table 3, according to smoking status, patients were divided into former, never and current smoking groups. In the control group, the level of SF was $79.47 \pm 14.84,49.91$ \pm 7.62 and $121.15 \pm 9.10$, respectively (former vs never vs

Table 2 Comparison of Serum SF, CEA and CRP Levels Among the Three Groups

\begin{tabular}{|l|l|l|l|l|l|}
\hline & $\begin{array}{l}\text { Control } \\
\text { Group } \\
\mathbf{( N = 5 0 )}\end{array}$ & $\begin{array}{l}\text { Benign } \\
\text { Group } \\
\mathbf{( N = 5 0 )}\end{array}$ & $\begin{array}{l}\text { Lung Cancer } \\
\text { Group } \\
\mathbf{( N = 7 0 )}\end{array}$ & $\mathbf{F}$ & $\mathbf{P}$ \\
\hline CEA & $2.78 \pm 0.81$ & $3.04 \pm 1.26$ & $24.27 \pm 19.92^{* \#}$ & 3.15 & 0.002 \\
CRP & $3.12 \pm 2.18$ & $12.67 \pm 3.64^{* \#}$ & $26.14 \pm 10.02^{*}$ & 4.76 & 0.023 \\
SF & $90.92 \pm 20.30$ & $165.66 \pm 41.21^{*}$ & $244.43 \pm 97.60^{* \#}$ & 6.89 & 0.034 \\
\hline
\end{tabular}

Notes: $* P<0.05$ compared with the control group; ${ }^{\#} P<0.05$ compared with the benign lung disease group. current). The difference was statistically significant. In the benign group, the expression of CEA, CRP and SF in the current smoking group was higher than that in the former and never smoking groups, and the difference was statistically significant $(P<0.05)$. In the lung cancer group, the difference of CEA and SF in different smoking status groups was statistically significant. For gender, in the control group, SF expression was different in different gender groups $(P<0.05)$, and the expression of CRP and SF had a gender difference in the benign group $(P<0.05)$.

\section{Comparison of the Level of CEA, SF and} CRP Based on Types of Lung Cancer and TNM Stage

The patients were divided into adenocarcinoma and squamous cell carcinoma groups according to the type of lung cancer. As shown in Table 4. In the adenocarcinoma group, the levels of CEA, CRP and SF were 37.79 $\pm 16.69,13.59 \pm 3.60$ and $272.95 \pm 97.02$, respectively, and in the squamous cell carcinoma group, the levels of these three markers were $7.28 \pm 4.98,11.51 \pm 3.43$ and 208.55 \pm 87.16 , respectively $(P<0.05)$. We also analyzed the relationship between the CEA, SF and CRP expression and TNM stage, and the results showed that serum SF, CRP and CEA levels in the lung cancer III+IV group were higher than those in group $\mathrm{I}+\mathrm{II}(P<0.05)$.

\section{Multivariate Logistic Regression}

Taking serum CEA, CRP and SF levels as independent variables, and taking benign diseases and lung cancer as

Table 3 Comparison of SF, CEA and CRP Levels According to Smoking Status and Gender

\begin{tabular}{|c|c|c|c|c|c|c|c|}
\hline & \multicolumn{3}{|c|}{ Smoking Status } & \multirow[t]{2}{*}{$P$} & \multicolumn{2}{|l|}{ Gender } & \multirow[t]{2}{*}{$\mathbf{P}$} \\
\hline & Former & Never & Current & & Female & Male & \\
\hline \multicolumn{8}{|l|}{ Control group } \\
\hline CEA (ng/mL) & $2.95 \pm 0.39$ & $2.585 \pm 0.13$ & $3.39 \pm 1.74$ & 0.52 & $2.58 \pm 0.13$ & $3.08 \pm 0.91$ & 0.377 \\
\hline CRP (ng/mL) & $2.4 I \pm 1.05$ & $4.29 \pm 2.09$ & $5.5 I \pm 4.18$ & 0.35 & $4.77 \pm 3.98$ & $3.98 \pm 2.01$ & 0.61 \\
\hline $\mathrm{SF}(\mathrm{ng} / \mathrm{mL})$ & $79.47 \pm 14.84$ & $49.91 \pm 7.62$ & $121.15 \pm 9.10$ & 0.001 & $50.72 \pm 7.11$ & $111.01 \pm 18.54$ & 0.0001 \\
\hline \multicolumn{8}{|l|}{ Benign group } \\
\hline CEA (ng/mL) & $5.04 \pm 1.70$ & $4.02 \pm 1.72$ & $5.08 \pm 2.71$ & 0.02 & $4.96 \pm 3.05$ & $4.55 \pm 1.78$ & 0.601 \\
\hline CRP (ng/mL) & $27.59 \pm 30.92$ & $16.06 \pm 11.93$ & $26.55 \pm 11.53$ & 0.09 & $32.54 \pm 10.99$ & $18.26 \pm 17.66$ & 0.006 \\
\hline $\mathrm{SF}(\mathrm{ng} / \mathrm{mL})$ & || $9.3 \mid \pm 87.86$ & $74.42 \pm 29.38$ & $|62.3| \pm 9 \mid .27$ & 0.001 & $76.96 \pm 64.21$ & $135.10 \pm 8 \mid .03$ & 0.017 \\
\hline \multicolumn{8}{|l|}{ Lung cancer group } \\
\hline CEA (ng/mL) & $|4.34 \pm| 5.1 \mid$ & $5.6 \pm 2.98$ & $32.33 \pm 45.95$ & 0.013 & $7.8 \mathrm{I} \pm 9.95$ & $22.11 \pm 37.20$ & 0.639 \\
\hline CRP $(\mathrm{ng} / \mathrm{mL})$ & $7.09 \pm 3.44$ & $8.89 \pm 3.84$ & $8.96 \pm 4.58$ & 0.44 & $8.18 \pm 2.92$ & $8.75 \pm 4.36$ & 0.845 \\
\hline $\mathrm{SF}(\mathrm{ng} / \mathrm{mL})$ & $246.65 \pm 144.56$ & $166.62 \pm 99.27$ & $300.33 \pm|44.7|$ & 0.001 & $302.1 \pm 182.84$ & $233.15 \pm 133.24$ & 0.505 \\
\hline
\end{tabular}


Table 4 Comparison of SF, CEA and CRP Levels According to Tissue Types and TNM Stage

\begin{tabular}{|c|c|c|c|c|c|c|c|}
\hline & \multirow[t]{2}{*}{$\mathbf{N}$} & \multicolumn{2}{|c|}{ CEA (ng/mL) } & \multicolumn{2}{|c|}{ CRP (ng/mL) } & \multicolumn{2}{|l|}{ SF (ng/mL) } \\
\hline & & Median士SD & $P$ & Median士SD & $P$ & Median士SD & $P$ \\
\hline $\begin{array}{l}\text { Tissue types } \\
\text { Adenocarcinoma } \\
\text { Squamous cell carcinoma }\end{array}$ & $\begin{array}{l}39 \\
31\end{array}$ & $\begin{array}{l}37.79 \pm 16.69 \\
7.28 \pm 4.98\end{array}$ & 0.013 & $\begin{array}{l}13.59 \pm 3.60 \\
\mid 1.51 \pm 3.43\end{array}$ & 0.042 & $\begin{array}{l}272.95 \pm 97.02 \\
208.55 \pm 87.16\end{array}$ & 0.036 \\
\hline $\begin{array}{l}\text { TNM stage } \\
\text { I-II } \\
\text { III-IV }\end{array}$ & $\begin{array}{l}34 \\
36\end{array}$ & $\begin{array}{l}8.36 \pm 3.27 \\
49.25 \pm 12.42\end{array}$ & 0.042 & $\begin{array}{l}14.57 \pm 1.62 \\
37.24 \pm 5.12\end{array}$ & 0.031 & $\begin{array}{l}173.25 \pm 52.36 \\
322.15 \pm 62.35\end{array}$ & 0.028 \\
\hline
\end{tabular}

Table 5 Multivariate Logistic Regression

\begin{tabular}{|l|l|l|l|l|}
\hline & $\boldsymbol{\beta}$ & OR & $\mathbf{9 5 \%} \mathbf{C l}$ & $\boldsymbol{P}$ \\
\hline CEA & 0.162 & 1.182 & $0.889-0.009$ & 0.042 \\
CRP & 0.752 & 2.109 & $1.266-2.942$ & 0.002 \\
SF & 0.005 & 1.005 & $1.001-1.021$ & 0.037 \\
\hline
\end{tabular}

dependent variables, a multivariate logistic regression model was established. The results showed that serum CEA, CRP and SF levels were independent risk factors for patients with lung cancer. With the increase of serum CEA level, the risk of lung cancer was 1.182 times higher than that of benign lung disease. While for CRP and SF, the risks were 2.109 and 1.005 , respectively. As shown in Table 5.

Comparison of diagnostic efficacy of combined or single detection of serum CEA, CRP and SF levels in patients with NSCLC and serum concentration CEA, CRP and SF levels in NSCLC and benign lung diseases were evaluated. ROC curve and results are shown in Figure 1 and Tables 6 and 7. First, the sensitivity and specificity of the single index was analyzed, and the results showed that the sensitivity of CEA, CRP and SF was $54.6 \%, 81.8 \%$ and $65.2 \%$ and the specificity was $87.5 \%, 66.8 \%$ and $87.5 \%$. The cutoffs of CEA, CRP and SF were 7.15, 8.27 and 139.03,

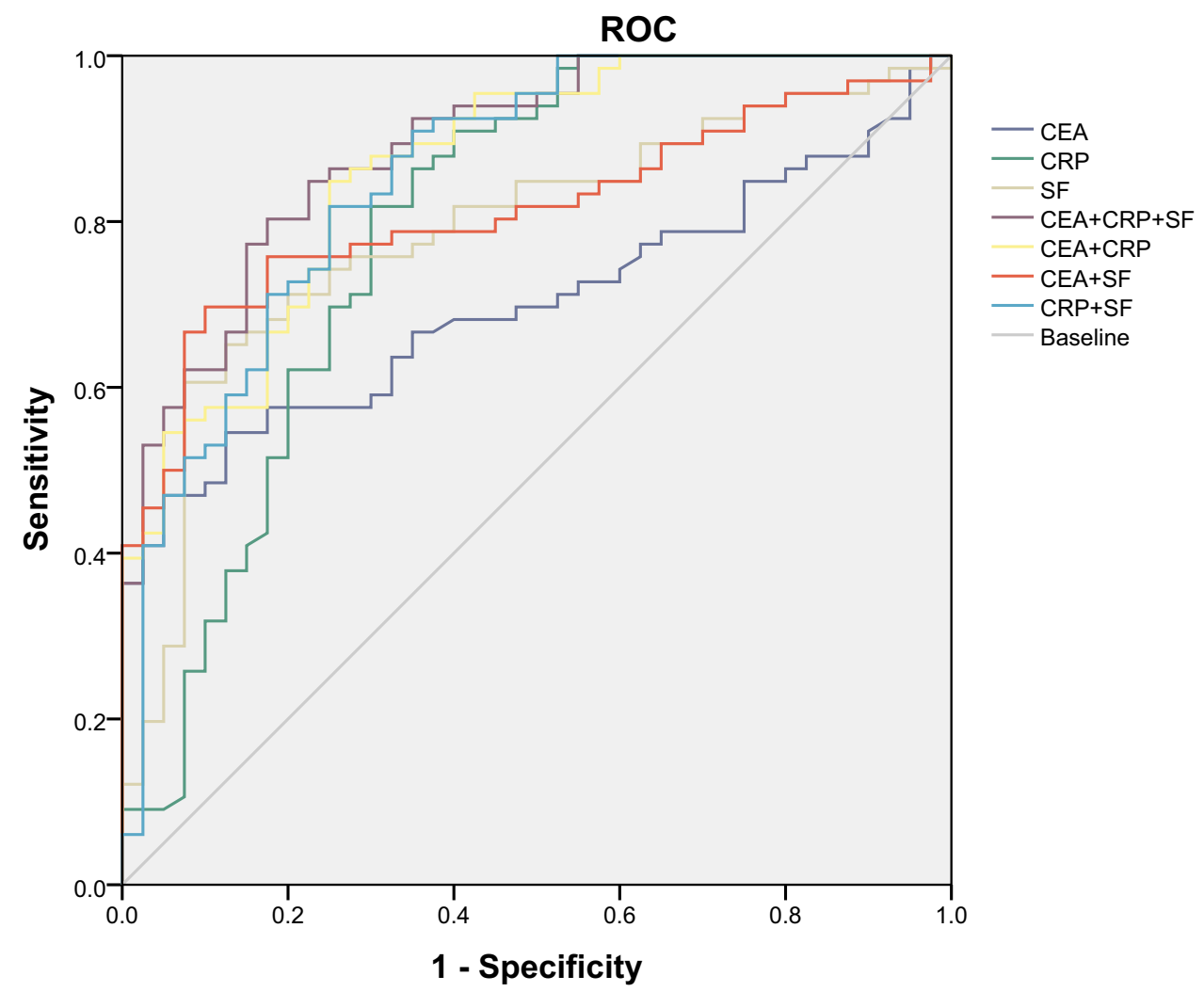

Figure I ROC curve of serum CEA, SF, and CRP in different groups. 
Table 6 Sensitivity and Specificity of Serum Markers in the Lung Cancer Group by Single Detection

\begin{tabular}{|l|l|l|l|l|l|l|}
\hline & Sensitivity (\%) & Specificity (\%) & AUC & Cut-off & $P$ & $\mathbf{9 5 \%}$ Cl \\
\hline CEA & 54.6 & 87.5 & 0.701 & 7.15 & $<0.001$ & $0.604-0.798$ \\
CRP & 81.8 & 66.8 & 0.795 & 8.27 & $<0.001$ & $0.698-0.891$ \\
SF & 65.2 & 87.5 & 0.788 & 139.03 & $<0.001$ & $0.699-0.877$ \\
\hline
\end{tabular}

Table 7 Comparison of Sensitivity and Specificity of Serum Markers in the Lung Cancer Group by Combined Detection

\begin{tabular}{|l|l|l|l|l|l|l|}
\hline & Sensitivity (\%) & Specificity (\%) & AUC & Youden's Index & $P$ & $\mathbf{P 5 \%}$ CI \\
\hline CEA+CRP & 84.8 & 75 & 0.866 & 0.012 & $<0.001$ & $0.798-0.935$ \\
CEA+SF & 69.7 & 90 & 0.813 & 0.97 & $<0.001$ & $0.732-0.894$ \\
CRP+SF & 81.8 & 75 & 0.856 & 0.011 & $<0.001$ & $0.780-0.932$ \\
CEA+CRP+SF & 80.3 & 82.5 & 0.890 & 0.00012 & $<0.001$ & $0.829-0.951$ \\
\hline
\end{tabular}

respectively. Second, the results of the combined diagnosis of the two factors were analyzed, the sensitivity of combined detection of CEA+CRP, CEA $+\mathrm{SF}$ and $\mathrm{CRP}+\mathrm{SF}$ was $84.8 \%, 69.7 \%$ and $81.8 \%$ and the specificity was $75 \%$, $90 \%$ and $75 \%$, respectively. Finally, the sensitivity and specificity of the three indexes were $80.3 \%$ and $82.5 \%$ respectively. The area under the ROC curve of the combination of the three indexes was 0.890 (95\% CI: 0.829 0.951 ), which was higher than that of the single index and two indexes.

\section{Discussion}

NSCLC is one of the most common malignant tumors in the respiratory system. ${ }^{13}$ Due to the lack of specific symptoms in the early stage of lung cancer, there is a lack of effective and rapid means of diagnosis. In recent years, with the rapid development of molecular biology, the detection of tumor markers has been widely used in tumor screening, diagnosis, efficacy evaluation and prognosis monitoring. ${ }^{14,15}$ Hematology examination has the advantages of small trauma and simple operation for patients. At present, it mainly relies on several sensitive and specific tumor markers to make auxiliary diagnosis for early tumor, but its detection rate for tumor is limited, ${ }^{16,17}$ A large number of studies have found that multiparameter combined diagnosis can improve the sensitivity and specificity of disease diagnosis. ${ }^{16}$ Therefore, this study aims to provide an auxiliary method for clinical diagnosis of lung cancer through multiparameter combined analysis of CEA, CRP and SF.

In the present study, we analyzed the concentrations of the CEA, CRP and SF in NSCLC, benign lung disease and healthy subjects. We demonstrated that the serum concentrations of SF, CEA and CRP in the NSCLC group were significantly higher than those in the benign lung disease group and control group. This fiding is in agreement with the study of other authors. Furthermore, we classify NSCLC into adenocarcinoma and squamous cell carcinoma according to the type of cancer. The result also showed that the concentrations of CEA, SF and CRP in adenocarcinoma were higher than in squamous cell carcinoma. Our results are in agreement with the findings of Shiels et al and Chen et al who also show that the serum concentrations of the above factors are highly expressed in patients with lung cancer. ${ }^{17,18}$ The main mechanism of result is that tumor development is closely related to inflammation. ${ }^{19}$ The expression of CRP and SF was related to inflammatory reaction. Thus, these two factors are higher in cancer patients. ${ }^{20,21} \mathrm{CEA}$ is a broad-spectrum tumor marker with a high positive rate in most tumor patients.

In this study, we also evaluated the diagnostic criteria, including sensitivity and specificity, and ROC curve for single and combination of these three factors. The diagnostic validity of CRP was significantly higher than that of SF and CEA. This result may be due to that for CEA, although it is a good tumor marker for the evaluation of curative effect, disease development, monitoring and prognosis of lung cancer, its specificity is not strong and sensitivity is not high. In addition, the serum CEA content of healthy patients and benign lesions is no more than 10 $\mathrm{ng} / \mathrm{mL}$. For SF, it is easy to be misdiagnosed because of the large fluctuation of SF in different subjects. Therefore, combination diagnosis is urgently needed. The results show that the detection efficiency of any combination of the above two factors is higher than that of single 
detection, and the combination of CRP, CEA and SF can achieve an increase of sensitivity and an insignificant decrease of specificity, which can be more convenient, fast, real-time detection of high-risk groups, with a good clinical reference value.

This study also has several limitations, Firstly, the age distribution was limited. The age of the enrolled subjects was 42-79 years, but the actual age for lung cancer had a downward trend. Secondly, only gender, age and smoking status were included in this study, and other confounding factors such as drinking and complications were not further studied. Finally, this study only established a preliminary diagnostic model, and further confirmatory research is needed.

\section{Conclusion}

The combination detection of CRP, CEA and SF can increase the early diagnostic accuracy of NSCLC, so as to provide basis for clinical treatment.

\section{Ethics Approval}

The study was deemed form ethical approval by the institutional review board of the First Affiliated Hospital of Xi'an Medical University (No. YW-LY-2016-022). Consent was obtained from all the participants prior to study commencement. All patients provided informed consent and that this study was conducted in accordance with the Declaration of Helsinki.

\section{Disclosure}

The authors declare no conflicts of interest for this work.

\section{References}

1. Faria N, Bruce FS, George AE. Lung Cancer. Med Clin N AM. 2019;103(3):463-473. doi:10.1016/j.mcna.2018.12.006

2. Yujiao X, Yi Z, Lutao D, et al. Circulating long noncoding RNA act as potential novel biomarkers for diagnosis and prognosis of non-small cell lung cancer. Mol Oncol. 2018;12(5):648-658. doi:10.1002/18780261.12188

3. Roy SH, Daniel M, Chris B. The biology and management of non-small cell lung cancer. Nature. 2018;553(7689):446-454.

4. Carlos Jordá A, Juan C, Peñalver C, et al. Mortality in early-stage, surgically resected non-small cell lung cancer less than $3 \mathrm{~cm}$ of size: competing risk analysis. Med Clin. 2015;145(5):185-191.
5. Veronica M, David M, Barbara H, et al. The prognostic strength of serum LDH and serum ferritin in children with neuroblastoma: a report from the International Neuroblastoma Risk Group (INRG) project. Pediatr Blood Cancer. 2020; 28359.

6. Zhongqing C, Bo Z, Chao O, Yuxuan L. Serum ferritin and primary lung cancer. Oncotarget. 2017;8(54):21518-92651.

7. Grunnet M, Sorensen JB. Carcinoembryonic antigen (CEA) as tumor marker in lung cancer. Lung Cancer. 2012;76(2):138-143. doi:10.1016/j.lungcan.2011.11.012

8. Li-Xin W, Xiao-Feng L, Hua-Fei C, et al. Combined detection of CEA and CA125 for the diagnosis for lung cancer: A meta-analysis. Cell Mol Biol. 2018;64(15):67-70. doi:10.14715/cmb/2017.64.15.11

9. Han W, Meng-Sen W, Yong-Heng Z, et al. Prognostic values of LDH and CRP in cervical cancer. OncoTargets Ther. 2020;13:1255-1263. doi: $10.2147 /$ OTT.S235027

10. Daniel CM, Devika RJ, Andrew HM, et al. Tumor mutation burden and depression in lung cancer: association with inflammation. $J$ Natl Compr Canc Ne. 2020;18(4):434-442. doi:10.6004/jnccn.2019.7374

11. Monika S, Piotr R, Aneta K, et al. Prognostic value of serum C-reactive protein (CRP) and cytokeratin 19 fragments (Cyfra 21-1) but not carcinoembryonic antigen (CEA) in surgically treated patients with non-small cell lung cancer. Pneumonol Alergol Pol. 2014;82 (5):422-429. doi:10.5603/PiAP.2014.0055

12. Ae Rin B, Hyun Jung S, June Hyuk L, et al. Prognostic value of baseline carcinoembryonic antigen and cytokeratin 19 fragment levels in advanced non-small cell lung cancer. Cancer Biomark. 2018;22(1):1255-1263.

13. Jean-Charles S, Yuichiro O, Johan V, et al. Osimertinib in untreated EGFR-mutated advanced non-small-cell lung cancer. $N$ Engl $\mathrm{J}$ Med. 2018;378(2):113-125. doi:10.1056/NEJMoa1713137

14. Faria SC, Sagebiel T, Patnana M, et al. Tumor markers: myths and facts unfolded. Abdom Radiol. 2019;44(4):1575-1600. doi:10.1007/ s00261-018-1845-0

15. Wei X, Yunfeng Z, Mei X, et al. The relationship between tumor markers and pulmonary embolism in lung cancer. Oncotarget. 2017;8 (25):41412-41421. doi:10.18632/oncotarget.17916

16. Hengmin J, Liang Z, Baolong W. The value of combination analysis of tumor biomarkers for early differentiating diagnosis of lung cancer and pulmonary tuberculosis. Ann Clin Lab Sci. 2019;49(5):645-649.

17. Meredith SS, Ruth MP, Allan H, et al. Circulating inflammation markers and prospective risk for lung cancer. $J$ Natl Cancer I. 2013;105(24):1871-1880. doi:10.1093/jnci/djt309

18. Zhongqing C, Bo Z, Chao O, et al. Serum ferritin and primary lung cancer. Oncotarget. 2017;8(54):92643-92651. doi:10.18632/ oncotarget. 21518

19. Anne M, Carine D, Céline C, et al. Anti-TNF, a magic bullet in cancer immunotherapy? J Immuno Cancer. 2019;7(1):303. doi:10.1186/s40425-019-0802-y

20. Kristine HA, Børge GN. Elevated C-reactive protein in the diagnosis, prognosis, and cause of cancer. Crit Rev Cl Lab Sci. 2011;48 (4):155-170. doi:10.3109/10408363.2011.599831

21. Naleen Raj B, Niranjan K, Corey H, et al. Reliability and validity of SF-12v2 among adults with self-reported cancer. RSAP. 2018;14 (11):1080-1084. doi:10.1016/j.sapharm.2018.01.007 


\section{Publish your work in this journal}

Cancer Management and Research is an international, peer-reviewed open access journal focusing on cancer research and the optimal use of preventative and integrated treatment interventions to achieve improved outcomes, enhanced survival and quality of life for the cancer patient.

The manuscript management system is completely online and includes a very quick and fair peer-review system, which is all easy to use. Visit http://www.dovepress.com/testimonials.php to read real quotes from published authors. 